\title{
Nail haemorrhages
}

\author{
DONALD HEATH AND DAVID REID WILLIAMS
}

From the Department of Pathology, University of Liverpool

SUMMARY Observations on the personnel in our laboratory, and two previously published studies make it clear that small nail haemorrhages are common and are not necessarily indicative of disease. Their site of origin and aetiology have not been studied and established. We investigated the incidence, site, and movement of such haemorrhages in one of us who is in good health and right-handed. The haemorrhages take place from capillaries in the centre of whorls of squamous epithelium beneath the deep soft nail plate. They develop at the line of separation of the nail plate from the nail bed and thus appear to be traumatic in origin. They were commoner in the first three fingers of both hands, that is in the digits most subjected to minor trauma in the subject studied. With the passage of time they move superficially and outwards to the nail margin. Histochemical studies of nail parings confirm that the linear discolorations are derived from blood. Their pathogenesis resembles that of 'black heel' in children. Nail haemorrhages are clearly not pathognomonic of subacute bacterial endocarditis and may occur in healthy subjects as the result of minor trauma. Nevertheless, recognition of this fact should not lead the clinician to ignore out of hand the presence of nail haemorrhages for in some instances they may still be supportive evidence of infective endocarditis, especially if they are frequent and numerous. Each case must be considered on its merits.

Splinter haemorrhages beneath the nails constitute a classical clinical sign which was originally associated with a diagnosis of subacute bacterial endocarditis over half a century ago by Horder (1920). He said: 'Twice in the past few months I have found a minute petechia, in the form of a vivid linear splash of red at the side of the bed of a finger-nail, in cases in which there were, as yet, no skin petechiae to be found, and in which the diagnosis of infective endocarditis was doubtful, but later established'. It is now generally accepted that such nail haemorrhages may form supportive evidence of infective endocarditis, especially when they are frequent and numerous.

However, it is also widely recognised that nail haemorrhages are not pathognomonic of subacute bacterial endocarditis. We became aware of this during an expedition to the Peruvian Andes in 1975 when we noted that many of the Quechua Indians living in the vicinity of Cerro de Pasco at an altitude of $4330 \mathrm{~m}$ above sea level had haemorrhages in their fingernails (Heath and Williams, 1977) (Fig. 1). Even more impressive were the haemorrhages that we found in the nails of highlanders suffering from Monge's disease (chronic mountain sickness), some of whom had as many as

Received for publication 19 December 1977
10 haemorrhages scattered throughout the nail (Heath and Williams, 1977). We became further interested when we read the report of Drummond Rennie (1974) that on an expedition to Dhaulagiri, Nepal $(8170 \mathrm{~m})$, the sixth highest mountain in the world, he developed haemorrhages in his fingernails. This newfound interest in the fingernails led us to maintain a close observation on our own nails when we returned from Peru to Liverpool. It soon became clear that the propensity to develop haemorrhages in the nails was not confined to the descendants of the Incas or to high altitude climbers but was shared by lowlanders. Both of us who had been to the Andes had recurrent haemorrhages in the nails on return to Merseyside. When it subsequently transpired that the senior chief technician and a secretary in our department also had recurrent nail haemorrhages (Fig. 2), we thought it would be of interest to study their incidence and site of origin.

\section{Methods of study}

We studied the incidence, site of origin on the nail, and movement of haemorrhages in the finger and toenails in one of the authors (D.H.) from 1 January to 30 June 1977. All haemorrhages were photographed on the day of their appearance and subsequently at intervals of 5 days. A line diagram, 1300 


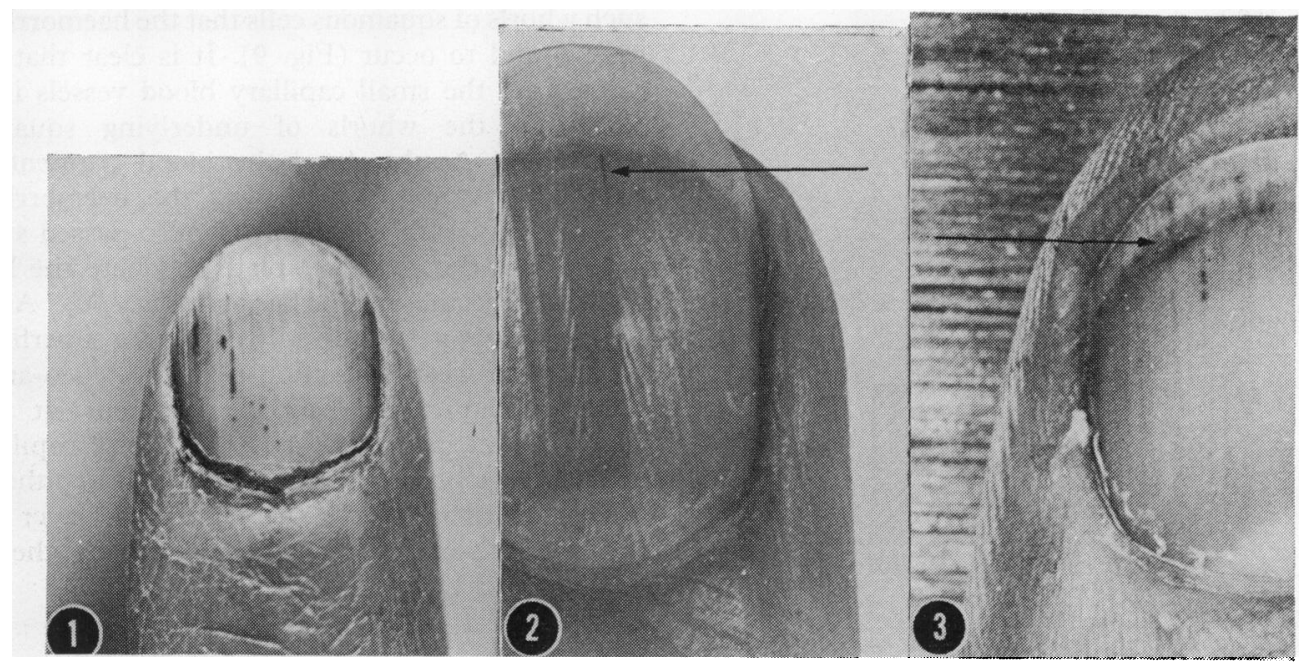

Fig. 1 Nail haemorrhages in a Quechua Indian native to Cerro de Pasco at an altitude of $4330 \mathrm{~m}$ in the Peruvian Andes. $(\times 1 \cdot 6$.)

Fig. 2 Nail haemorrhage in the third right finger in the right-handed 24-year-old secretary of one of the authors. The linear haemorrhage (arrow) occurs at the line of separation of nail plate from nail bed. $(\times 3 \cdot 2$.

Fig. 3 Linear haemorrhage in the right thumb nail of one of the authors (D.H.) on 22 April 1977. There is a row of nail haemorrhages at the line of separation of the nail plate from underlying nail bed (arrow). $(\times 3 \cdot 2$.

at a magnification of $\times 4$, was made from a lifesized photograph of each nail. A grid, with vertical and horizontal lines $2 \mathrm{~mm}$ apart, was drawn on this diagram. The composite diagram and grid were drawn on transparent film and superimposed over photographic prints of nails showing haemorrhages to facilitate measurements of their size, site, and movement.

When a haemorrhage had grown to the edge of the nail, the paring containing it was sectioned and stained, to confirm its nature and to determine its site of origin. To prepare satisfactory thin sections of nail it is necessary to use methacrylate-embedded material. The parings were dehydrated up to absolute alcohol by normal processing schedules and then left overnight in a solution of 2-hydroxyethylmethacrylate, 2-butoxyethanol, and benzoyl peroxide. The nail was then cast in 42 parts of this mixture with 1 part of polyethylene glycol and NN dimethylaniline. Polymerisation occurred in 30 minutes and then blocks were trimmed with a hacksaw and attached to a wooden block with beeswax. Sections were cut on a base sledge microtome and the technique described allowed the production of sections some 2 to $4 \mu \mathrm{m}$ in thickness. After being placed in an incubator at $60^{\circ} \mathrm{C}$ for at least one hour the sections were stained with haematoxylin and eosin, and with Van Gieson's stain.

The sections were also stained by the leucoaniline blue technique which indicates the presence of peroxidase which is associated with erythrocytes. Aniline blue is reduced, and thus decolorised, with nascent hydrogen to leuco-aniline blue. When this comes into contact with extravasated erythrocytes their contained peroxidase catalyses the transfer of oxygen from added hydrogen peroxide to the leuco form of the dye. Hence its blue colour returns indicating the presence of altered blood.

\section{Results}

\section{CLINICAL}

The haemorrhages were linear or, less commonly, punctate (Fig. 3). The former measured some $1.0 \times 0.25 \mathrm{~mm}$ while the latter were about $0.25 \mathrm{~mm}$ diameter. They did not develop at the root or throughout the nail but instead appeared in a line where the nail separates from the underlying nail bed (Fig. 3). With the passage of time the haemorrhages grew towards the nail edge, thus showing that they were within the substance of the nail and not petechiae. The nails were under observation for 182 days and moved at a rate of 0.14 to $0.19 \mathrm{~mm}$ 


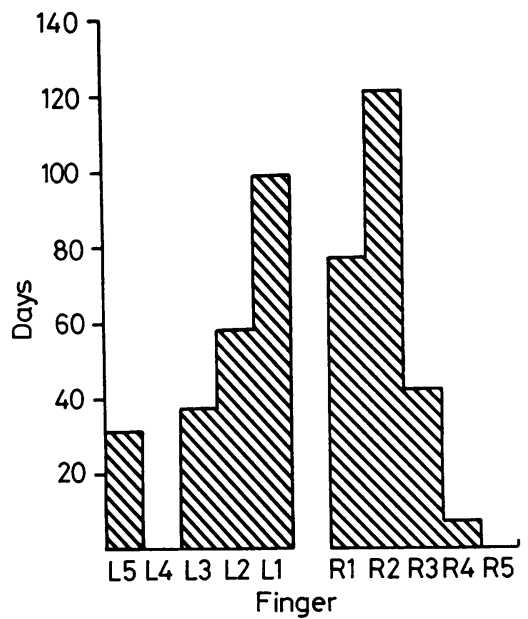

Fig. 4 The number of days on which haemorrhages were found in the fingernails of one of the authors (D.H.) over a period of six months from 1 fanuary 1977. Haemorrhages are seen to be commoner in the first three fingers of both hands and are somewhat more frequent in the right hand.

per day. If large, the haemorrhages persisted as linear streaks and subsequently became available for histological study in nail parings. Not infrequently, however, they became paler and fragmented as they passed to the nail edge, and below we comment on the histological appearances associated with this change. They were frequent in the first three fingers of both hands but much less common in the fourth and fifth fingers (Fig. 4). They were rare in the toenails, occurring on only one occasion in the right big toe during the 6-month period of study (Fig. 5). The haemorrhages were somewhat commoner in the right hand (Fig. 4), the subject studied being right-handed.

\section{HISTOCHEMICAL}

The leuco-aniline blue technique confirmed that the brown linear streaks in the nails contained peroxidase and were thus consistent with being altered blood.

\section{HISTOLOGICAL}

The thin sections of methacrylate-embedded nail parings revealed that the haemorrhages occurred deep in the nail plate where the undersurface of the nail separated from the nail bed. When methacrylate sections of nail are cut parallel to the surface one traverses at first the superficial hard nail plate (Fig. 6). Deeper sections in this plane reach the underlying softer nail plate (Fig. 7). Deeper sections still reveal the tips of upwardly projecting papillae of squamous cells (Fig. 8). It is at this level and in such whorls of squamous cells that the haemorrhages were found to occur (Fig. 9). It is clear that they came from the small capillary blood vessels in the centre of the whorls of underlying squamous epithelium. At this level the blood pigment was red and obvious. However, as the haemorrhages grew distally with the nail, they also passed superficially into the hard nail plate and here the blood pigment became much fainter (Fig. 10). As the haemorrhages passed distally and more superficially they gave a weaker reaction with the leuco-aniline blue technique. Methacrylate sections at right angles to the nail confirmed the blood capillaries in the centre of the whorls of squamous epithelium in the superficial part of the Malpighian layer to be the site of origin of haemorrhages in the nail (Fig. 11 and 12).

\section{Discussion}

Two alternative hypotheses have been advanced to explain the appearance of the splinter haemorrhages described by Horder (1920). Some have ascribed them to increased capillary fragility (White, 1947; Lewis, 1948) while others believe them to be embolic in origin (Bramwell and King, 1942). By 1956 Wood had come to the conclusion that nail haemorrhages were not diagnostic of bacterial endocarditis. Our studies confirm that most nail haemorrhages are not embolic in nature for they do not remain stationary under the nail bed. They move with the nail thus showing that they are in its substance.

Platts and Greaves (1958) were the first to show that nail haemorrhages are to be found in the course of many diseases. They examined the fingernails of 429 patients and normal subjects and 35 cadavers. They found nail haemorrhages in a wide range of diseases other than subacute bacterial endocarditis, such as mitral stenosis, malignant tumours, and various pulmonary diseases. More significantly they found nail haemorrhages in several of their healthy acquaintances. They formed the impression that the haemorrhages were especially liable to occur after repeated jarring of the hand. Thus they found them in the nails of an emphysematous diabetic who was employed in making packing cases.

Gross and Tall (1963) found nail haemorrhages in no less than $19 \cdot 1$ per cent of 267 hospital inpatients. They were found to occur more often in those patients whose occupations exposed their hands to frequent trauma. They occurred more frequently in persons who had recently been admitted to hospital and fresh from the wear-andtear of daily life and decreased with increasing length of duration in hospital when the patients had been at rest in bed. This suggested that the 


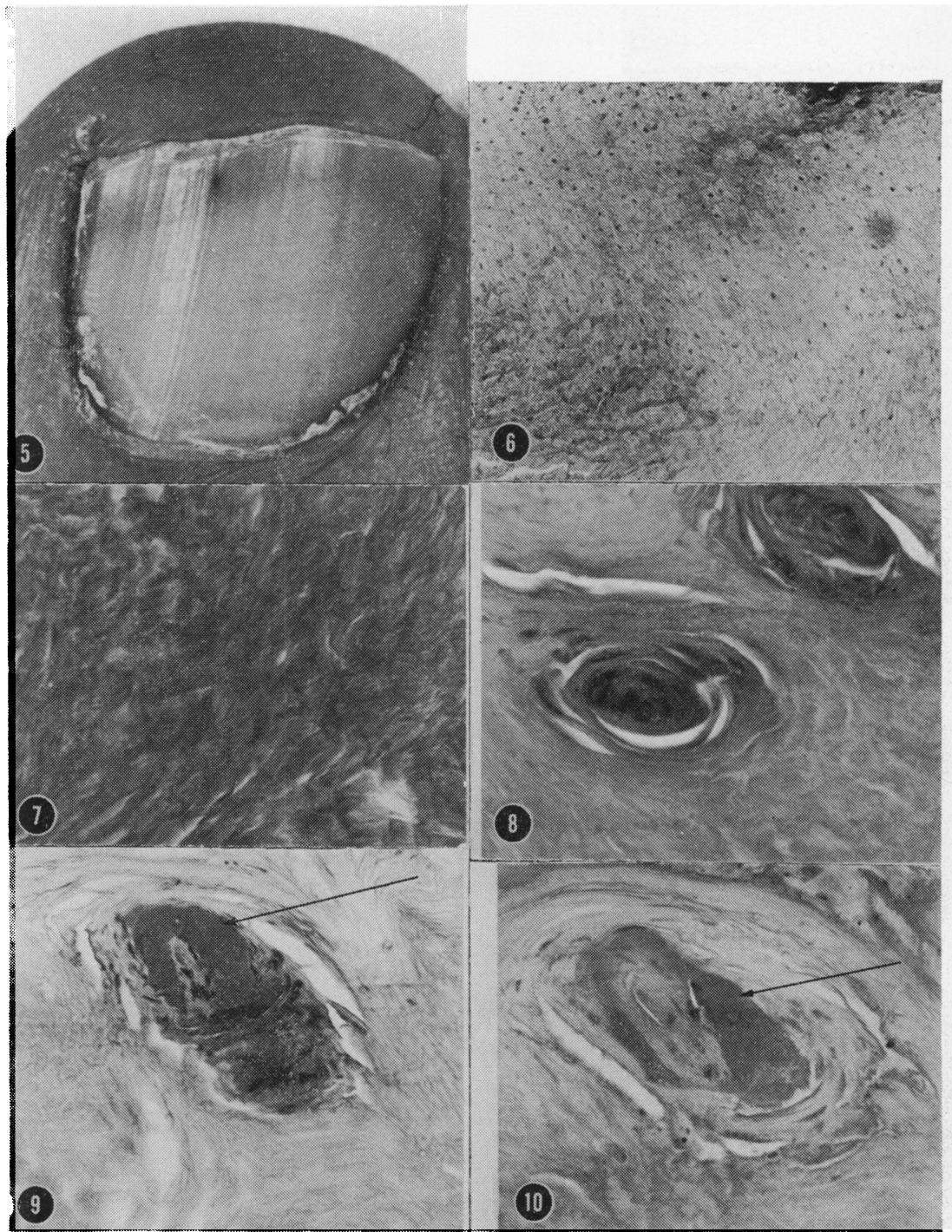

Fig. 5 Nail haemorrhage in the right big toe of one of the authors (D.H.) on 1 fanuary 1977. $(\times 2 \cdot 6$.

Fig. 6 Superficial hard, nail plate. (Methacrylate section. Haematoxylin and eosin. $\times 100$.)

Fig. 7 Deeper softer, nail plate. (Methacrylate section. Haematoxylin and eosin. $\times 250$.)

Fig. 8 Whorls of squamous cells in the deep plate. (Methacrylate section. Haematoxylin and eosin. $\times 400$.)

Fig. 9 Haemorrhage in the squamous whorls of the deep plate (arrow). (Methacrylate section. Haematoxylin and eosin. $\times 400$.)

Fig. 10 An older, paler haemorrhage in the hard nail plate (arrow). (Methacrylate section. Haematoxylin and eosin. $\times$.700.) 


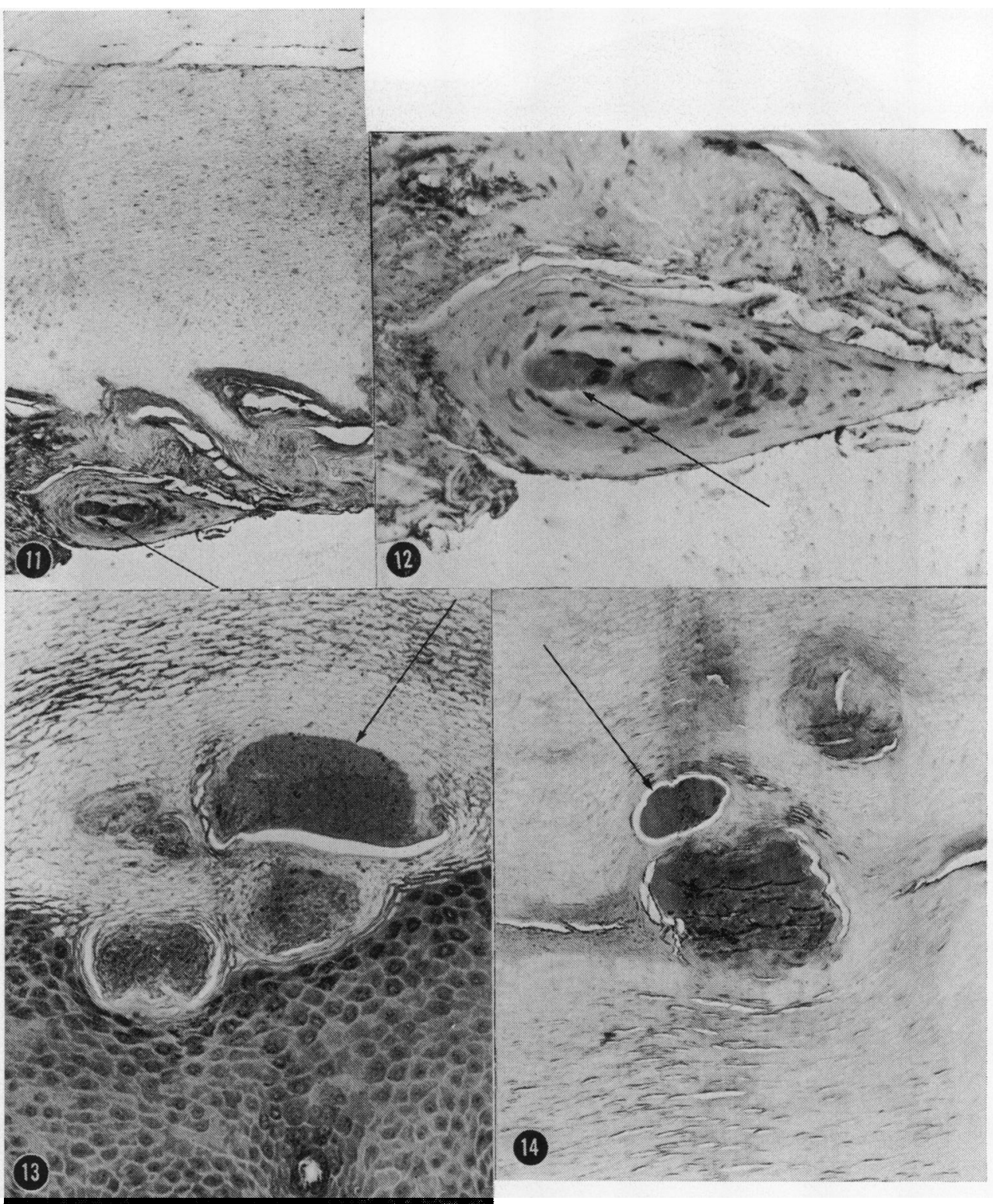

Fig. 11 Methacrylate section taken at right angle to nail showing haemorrhage in squamous epithelium (arrow). (Haematoxylin and eosin $\times 92$.)

Fig. 12 Haemorrhage in whorl of squamous cells underlying soft nail plate (arrow). (Haematoxylin and eosin $\times 240$.)

Fig. 13 Section of skin of heel from a case of 'black heel'. Haemorrhages (arrow) have appeared in the deep keratin layer immediately overlying the Malpighian layer. (Haematoxylin and eosin $\times 150$.)

Fig. 14 'Black heel'. The haemorrhages pass into the more superficial layers of keratin, gradually becoming paler. (Haematoxylin and eosin $\times 100$.) 
haemorrhages were traumatic in origin. Other details recorded such as age, sex, temperature, systemic blood pressure, capillary fragility, and haematuria appeared to be irrelevant. Rennie (1974) noted the appearance of 50 linear haemorrhages under his fingernails and thumb nails during a restful evening at $5880 \mathrm{~m}$ but it should be noted that in the previous 5 weeks he had been engaged in high altitude climbing.

We also believe that the nail haemorrhages are traumatic in origin, for most occurred at the line of separation of the nail from the bed. Perhaps they are associated with leverage of the nail plate as it is pushed away from the underlying nail bed. They were commoner in the first three fingers on both hands which are used and exposed to trauma far more than the fourth and fifth fingers in which haemorrhages proved to be unusual. In this investigation on a right-handed person they were commoner in the right hand. Furthermore, only one haemorrhage occurred in the toenails over a period of 6 months consistent with the fact that the toes are relatively static and protected from trauma by the shoes. It is of interest that the solitary haemorrhage in the right big toe occurred after four long car journeys necessitating frequent pressure of the right foot on the accelerator pedal.

The view that the brown linear streaks in the nails are caused by minor haemorrhages finding their way into the nail plate is supported by a similar process leading to 'black heel' (Wilkinson, 1972) (Fig. 13 and 14). In this lesion closely aggregated groups of bluish-black specks occur suddenly at the back or side of the heel, just above the hyperkeratotic edge. They occur largely in athletic adolescents, in whom they may resemble a tattoo or even a melanoma, and are believed to arise as a result of small haemorrhages occurring after minor trauma which rupture superficial capillaries in the dermis. Blood pigment is subsequently eliminated through the epidermis and horny layer (Fig. 13 and 14), giving the appearance of the small blackbrown marks.

It is our impression that the nail haemorrhages of highlanders are larger and originate lower down the nail (Fig. 1). It would be of interest to see if these differences from lowlanders are reproduced in patients exposed to hypoxaemia.

This study was supported by a grant from the Mersey Regional Research Committee. We are grateful to Robert Biggar for his expertise in cutting the methacrylate sections, and to Professor D. L. Gardner of the Department of Pathology of the University of Manchester for his comments on the manuscript.

\section{References}

Bramwell, C., and King, J. T. (1942). Principles and Practice of Cardiology, p. 386. Oxford University Press, London.

Gross, N. J., and Tall, R. (1963). Clinical significance of splinter haemorrhages. British Medical fournal, 2, 1496-1498.

Heath, D., and Williams, D. R. (1977). Man at High Altitude, pp. 18 and 138. Churchill Livingstone, Edinburgh.

Horder, T. (1920). Discussion on the clinical significance and course of subacute bacterial endocarditis. British Medical fournal, 2, 301-304.

Lewis, T. (1948). Diseases of the Heart, 4th ed. p. 189. Macmillan, London.

Platts, M. M., and Greaves, M. S. (1958). Splinter haemorrhages. British Medical fournal, 2, 143-144.

Rennie, D. (1974). Splinter haemorrhages at high altitude. fournal of the American Medical Association, 228, 974.

White, P. D. (1947). Heart Disease, 3rd ed., p. 360. Macmillan, New York.

Wilkinson, D. S. (1972). Black heel. In Textbook of Dermatology, 2nd ed., pp. 427-428. Ed. by A. Rook, D. S. Wilkinson, and F. J. G. Ebling. Blackwell Scientific, Oxford.

Wood, P. H. (1956). Diseases of the Heart and Circulation, 2nd ed., p. 648. Eyre and Spottiswoode, London.

Requests for reprints to Professor Donald Heath, Department of Pathology, New Medical School, University of Liverpool, Ashton Street, P.O. Box 147, Liverpool L69 3BX. 